\title{
Análise do processo participativo em projetos ambientais desenvolvidos em um bairro de Bauru/SP
}

Analysis of the participatory process in environmental projects in a district of Bauru, São Paulo, Brazil

\author{
Lucas André Teixeira ${ }^{1}$ \\ Marcela de Moraes Agudo ${ }^{2}$ \\ Jandira Liria Biscalquini Talamoni ${ }^{3}$
}

\section{Resumo}

Este trabalho buscou analisar a dimensão participativa em dois projetos ambientais que foram realizados em um bairro popular de Bauru/SP. Para a análise dos projetos ambientais, diante da diversidade de concepções e abordagens teórico-práticas de educação ambiental neles existentes, optamos pela fundamentação teórica inserida na vertente estabelecida como educação ambiental crítica. Assim, a análise e interpretação dos projetos delimitados tiveram o objetivo de contribuir para a dimensão participativa do processo educativo ambiental, buscando o aprofundamento da reflexão sobre alguns de seus princípios na perspectiva da educação ambiental crítica.

Palavras chave: projetos ambientais; processo participativo; educação ambiental.

\section{Abstract}

This study analyzed the participatory dimension in two environmental projects that were carried out in a popular district of Bauru, São Paulo, Brazil. For the analysis of environmental projects, given the diversity of concepts and theoretical and practical environmental education approaches contained therein, we chose inserted theoretical foundation in established aspect as critical environmental education. Thus, the analysis and interpretation of delimited projects had the objective of contributing to the participatory dimension of environmental education process, seeking to further reflection on some of its principles from the perspective of critical environmental education

Keywords: environmental projects; participatory process; environmental education.

\footnotetext{
${ }^{1}$ Universidade Estadual Paulista Julio Mesquita Filho, Campus Bauru/SP (UNESP/Bauru) | lucasandreteixeira@gmail.com

${ }^{2}$ Universidade Estadual Paulista Julio Mesquita Filho, Campus Bauru/SP (UNESP/Bauru) | marcelamagudo@gmail.com

${ }^{3}$ Universidade Estadual Paulista Julio Mesquita Filho, Campus Bauru/SP (UNESP/Bauru) | talamonii@fc.unesp.br
} 


\section{Introdução}

A educação ambiental é um processo educativo que objetiva a instrumentalização dos sujeitos para o enfrentamento das causas da crise sócio-ambiental, visando à emancipação das condições determinadas pelo modo de produção capitalista, agente determinante da crise socioambiental a que está submetida a humanidade.

Diante dos desafios e afrontamentos que estão postos pela realidade do mundo contemporâneo, especialmente no que tange à problemática ambiental, entendemos que a educação ambiental cumpre diversas funções na sociedade atual, sendo que tais funções estão, contraditoriamente, atreladas a concepções políticas e ideológicas que visam satisfazer o interesse de instituições políticas, comerciais, industriais, escolares, culturais, entre outras.

Assim, as abordagens filosófico-políticas que fundamentaram os projetos ambientais analisados tiveram como referência o princípio participativo e coletivo da pesquisa-açãoparticipativa para o desenvolvimento de ações ambientais no bairro. Tais ações proporcionaram fatores indicativos de impacto qualitativo no cotidiano escolar e na comunidade, do ponto de vista educativo. Nosso objetivo foi o de analisar a dimensão participativa que esses projetos adotaram como referencial teórico-metodológico para sua execução, buscando o aprofundamento da reflexão sobre alguns de seus princípios, como participação, coletividade e ação, na perspectiva da educação ambiental crítica.

\section{Fundamentos da Educação Ambiental Crítica}

A educação ambiental pode ser apropriada "a partir das diferentes abordagens teóricopráticas, formuladas e praticadas por diferentes grupos sociais, com interesses contraditórios histórica, social e politicamente determinados" (TOZONI-REIS, 2007a, p. 185). Neste sentido, entendemos ser necessária uma reflexão elaborada e rigorosa por parte dos educadores no modo de se conceber a educação ambiental para não cairmos em um "pluralismo indiferenciado" (LOUREIRO, 2004).

Para avançar em nossas discussões e justificarmos a concepção de educação ambiental que assumimos neste estudo diante de tal diversidade, nos remetemos aos estudos de Grün (2007). De acordo com o autor, que discute a epistemologia da educação ambiental a partir de uma concepção filosófica, a necessidade do predicado ambiental na educação surge devido à negação do ambiente na educação moderna. Assim, a utilização do predicado ambiental na educação tem um caráter histórico, é uma resposta da educação a uma crise da cultura ocidental cartesiana que, durante a modernidade, "esqueceu" o nosso vínculo indissociável com o ambiente, negando, assim, a própria história da humanidade.

Ainda segundo o autor, para construirmos uma reflexão no campo epistêmico da educação ambiental temos que resignificar os valores do racionalismo moderno, sob o qual repousam as principais características da crise ecológica proporcionada pelo capital que, consequentemente, determina e estimula a relação inadequada da humanidade com o seu entorno.

Assim, podemos afirmar que o racionalismo cartesiano, que se desenvolveu durante toda a idade moderna, criou um contexto favorável para o desenvolvimento do capitalismo, onde as "relações de mercado, natureza e lógica temporal antropocêntrica passam a formar um sistema complexo de inter-relações" (GRÜN, 2007, p.25). Desta maneira, o racionalismo 
humano passou a mercantilizar a natureza, criando um lócus que proporcionou as bases para o desenvolvimento do capitalismo.

O racionalismo cartesiano provocou uma cisão radical entre o sujeito e o objeto, lógica na qual se baseou todo o conhecimento científico da idade moderna, assim como toda a cultura ocidental (GRÜN, 2007). Essa lógica transformou a natureza em objeto e o homem passou a dominá-la para poder explorá-la, apossando-se da mesma e, conseqüentemente, distanciando-se dela. Essa lógica também favoreceu o desenvolvimento da sociedade capitalista e, ao longo de seu desenvolvimento, chegou a determinar a exploração do homem pelo homem (LOUREIRO, 2004, p. 94), em que os bens são produzidos não para atender às necessidades humanas de sobrevivência, mas com a utilidade definida no domínio do valor de troca.

Este espectro que rondava a modernidade influenciou profundamente a educação moderna. Para tornar-se humano o homem deveria dominar a natureza e libertar-se a si mesmo. Assim, o desenvolvimento das ciências naturais baseou-se na distinção entre o sujeito e o objeto na medida em que o pensamento curricular passou a se fundamentar em uma lógica pragmática, individualista e racionalista, estruturas que consideravam a natureza apenas quanto ao seu valor de uso (GRÜN, 2007).

A consolidação da influência da racionalidade moderna na educação é efetivada com a mecânica newtoniana que estabeleceu uma nova visão de mundo, na qual todas as explicações se baseavam no modelo explicativo da mecânica clássica. Sobre esse aspecto, Grün diz que:

A possibilidade de uma descrição objetiva da natureza estabelecida pelo programa newtoniano não define um simples conceito de natureza. Esta possibilidade define um modelo de interpretação do mundo sustentado no modelo explicativo mecânico-causal. O modelo atomístico reducionista estabelecerá nas estruturas conceituais dos currículos e, mais do que isso, ele passará a ser a única forma possível de conceber a realidade. De um certo modo, ele passa a ser a própria realidade. Neste período todo um corpo de saberes ecologicamente sustentáveis é deixado de lado no currículo por não ser científico, ou seja, por não ser mecanicista. (GRÜN, 2007, p. 41).

Diante disso, podemos concluir que a racionalidade moderna suprimiu diversos valores que eram contrários ao paradigma mecanicista e muitos dos saberes que não se enquadravam neste paradigma foram negados. Sob esta perspectiva, entendemos que a problemática ambiental se estruturou e se intensificou a partir da racionalidade moderna e que é

[...] um problema estrutural, vinculado ao modelo de desenvolvimento, ao modo de produção, à baixa participação política e cidadã nas questões vistas como ambientais, à conjunção do Estado aos interesses privados e mercantis, e ao reducionismo no tratamento da categoria ambiente. (LOUREIRO, 2004, p. 82).

Diante da diversidade de propostas teóricas produzidas no âmbito da educação ambiental, cabe questionar qual a contribuição das mesmas, em termos prospectivos, para propor uma reversão ou buscar respostas para a problemática ambiental. Entendemos que a negação da homogeneidade simplificadora e o respeito à diferença de idéias são imprescindíveis e coerentes com a visão de ambiente enquanto complexidade do mundo, 
pois ele é decorrente de múltiplas determinações, entretanto, ao defender o diverso, não se pode cair num pluralismo indiferenciado, o que seria um erro (LOUREIRO, 2004).

Portanto, qualquer proposta ou atividade de educação ambiental que adote uma perspectiva de enfrentamento radical da problemática ambiental deve ser mediada a partir de reflexões sobre os seus fundamentos e conceitos, com a devida coerência, para que esta não acabe legitimando as contradições produzidas pelo modo de produção capitalista, que muitas vezes nem são trazidas à tona pelos projetos que tematizam o ambiente.

É neste sentido que entendemos a necessidade de rigorosa reflexão sobre os fundamentos teóricos da educação ambiental, para problematizar as tendências teóricas e as práticas educativas, proporcionando a reflexão de suas contradições e, consequentemente, apontando para a necessidade de mudança qualitativa nos processos determinantes da problemática ambiental que se materializa na organização social.

Diante das diversas concepções e abordagens teórico-práticas existentes no modo de conceber a educação ambiental, acreditamos que os princípios da educação ambiental crítica podem criar condições para esse enfrentamento da crise estrutural que estamos vivenciando a cada dia. Assim, entendemos a educação ambiental crítica como:

[...] um processo político de apropriação crítica e reflexiva de conhecimentos, atitudes, valores e comportamentos que tem como objetivo a construção de uma sociedade sustentável do ponto de vista ambiental e social - a educação ambiental transformadora e emancipatória. (TOZONI-REIS, 2007a, p. 179).

Diante do exposto, buscamos uma coerência teórica para não incorrermos em formulações simplificadoras da realidade sócio-ambiental. Nesse sentido, passamos a discutir o processo educativo ambiental e a participação.

\section{A dimensão participativa no processo educativo ambiental}

Um aspecto a ser considerado no processo educativo ambiental refere-se à relação dialógica e participativa entre a escola e a comunidade, pois, embora no discurso esta participação possa estar enfatizada, sabemos de sua fragilidade. O ponto fulcral está na qualidade da articulação e da participação, comprometendo a capacidade de atuação dos sujeitos envolvidos nos processos dialógicos de organização, comunicação e decisão.

Alguns sinais desses aspectos emergiram da análise realizada pelo Projeto $O$ que fazem as escolas que dizem que fazem Educação Ambiental (TRAJBER e MENDONÇA, 2006) que objetivou conhecer e avaliar as práticas de educação ambiental em 418 escolas públicas e particulares do ensino básico, localizadas em dois estados de cada uma das cinco regiões brasileiras. Os dados apresentados no documento em questão tendem a reforçar a necessidade de uma crescente busca, no âmbito das instituições escolares, por mecanismos de inclusão da comunidade do entorno e pela superação das dificuldades nas relações entre a escola e a comunidade, e a baixa politização e participação do processo educativo ambiental, como podemos observar neste fragmento:

[...] é possível afirmar que há preocupação crescente frente a essa questão da relação com a comunidade. Tanto é que os projetos têm procurado aumentar a viabilidade da interação, inserindo atividades que priorizem as necessidades da comunidade. Porém, as escolas ainda têm grande dificuldade em estabelecer metodologias mais participativas na 
elaboração e gestão dos projetos e na construção do Projeto Político Pedagógico, e de aceitar que os atores sociais comunitários são igualmente sujeitos do processo educativo ambiental. (TRAJBER e MENDONÇA, 2006, p. 191).

Embora algumas iniciativas e práticas educativas estabeleçam uma preocupação com os problemas ambientais relacionados ao cotidiano da comunidade, percebe-se que as ações ambientais não têm contemplado de maneira efetiva o aspecto educativo da educação ambiental. Assim, apesar de as ações visarem a uma aproximação da escola com a comunidade para o enfrentamento de seus problemas, não têm conseguido garantir plena participação da comunidade, enquanto sujeitos do processo educativo.

A transformação social, enquanto processo histórico, coloca para a pesquisa em educação ambiental a importância da continuidade e da permanência das práticas educativas que instrumentalizem a prática social dos sujeitos. Nesta perspectiva, as pesquisas em educação ambiental têm que ser pautadas em procedimentos teóricometodológicos que vão além da pesquisa em si, favorecendo a continuidade dos envolvidos no projeto e permitindo uma apropriação coletiva de instrumentos que thes possibilitarão o enfrentamento da problemática ambiental nos níveis local, regional e global.

Neste mesmo sentido, a perspectiva de continuidade para os envolvidos traz à tona a participação como sendo um dos princípios fundamentais recorrente nas práticas educativas da educação ambiental, considerada como uma categoria central nas pesquisas deste campo. Entretanto, quando colocamos a importância da instrumentalização para a continuidade efetiva dos projetos que tematizam o ambiente, temos que pensar sobre como o processo participativo se desenvolve.

Os envolvidos no projeto coletivo e participativo não podem ser meros informantes em determinados contextos ou, ainda, apenas componentes de um grupo. Um processo participativo, que se diz democrático, não pode simplesmente dar voz (VIEZZER, 2005), é preciso permitir que a instrumentalização dos sujeitos envolvidos thes possibilite refletir, estudar, teorizar e debater as questões das quais são excluídos, para que não Ihes seja negado o poder de decisão, colocando-os como sujeitos do processo histórico. Daí a necessidade da fundamentação pedagógica para as práticas educativas na educação ambiental.

Este ponto de vista vincula a educação ambiental, especificamente, ao enfrentamento pedagógico da questão ambiental, pois a pedagogia "como ciência da e para a educação, se preocupa com a compreensão teórica e prática dos processos educativo-formativos e diz respeito aos saberes e modos da ação voltados para a formação humana" (TOZONI-REIS, 2007a, p. 186).

Este desafio requer uma reflexão categórica com o objetivo de ultrapassar as práticas pontuais e imediatistas que querem mudar o pensamento e o comportamento sem mudar a realidade objetiva, ou seja, a organização social. É nesta ótica que nos fundamentamos para realizar as análises deste estudo.

\section{Metodologia}

Para o desenvolvimento deste estudo adotamos os procedimentos metodológicos da abordagem qualitativa de pesquisa em ciências humanas e sociais. Desta maneira, é oportuno tecermos uma breve consideração histórica para fundamentarmos tal adoção. 
Ao longo do século XIX, apesar da influência da racionalidade dominante das ciências naturais, as ciências sociais começaram a enveredar-se por um caminho distinto, no qual o seu objeto passou a ser considerado essencialmente qualitativo, definindo assim a sua especificidade. É oportuno ressaltar, pois, que os objetivos dessas duas ciências são diferentes - mas não incompatíveis - bem como seus métodos.

O campo de estudos da metodologia qualitativa de pesquisa começou a se estabelecer, num primeiro momento, nas pesquisas antropológicas e sociológicas no limiar do século XIX, ganhando corpus no final deste período, quando as denúncias sociais passaram a ganhar destaque, chamando a atenção para as condições de vida subumanas às quais estava submetida grande parcela da sociedade. Tais estudos deram relevância a temas como pobreza, condições de trabalho, saúde, urbanização e educação, entre outros (BOGDAN; BIKLEN, 1991).

A metodologia qualitativa de pesquisa, assim, busca o enfrentamento dos problemas apresentados pela realidade, os quais desafiam o homem à análise e reflexão, objetivando contribuir, no campo da produção de conhecimentos, na busca de alternativas para a superação dos mesmos. Eis aí a influência da pesquisa qualitativa no campo educacional, quando, no princípio do século XX, começou a ganhar amplo espaço. Esta fase foi marcada pela grande influência dos etnógrafos, que desenvolveram metodologias próprias e caracterizadas pela participação, observação, interrogação e descrição da realidade investigada. A consolidação desta metodologia de pesquisa ganhou espaço significativo no campo educacional a partir da década de 1970, aumentando sua tendência nas décadas seguintes, passando por modificações importantes e significativas dos pontos de vista técnico e conceitual.

Entre os principais motivos que levaram à utilização da pesquisa qualitativa nos estudos que envolvem os fenômenos educacionais é apontado o fato de que apenas os métodos quantitativos não são adequados e suficientes para responder aos problemas específicos da educação, na medida em que eles exigem ser compreendidos pela análise interpretativa, pela reflexão dos dados da realidade empírica através de reflexões do pensamento que exigem posicionamento teórico pois não podem ser descontextualizados.

Não obstante, percebemos que a influência do racionalismo moderno impera marcadamente nos estudos educacionais. Os fenômenos educacionais foram e, de certa forma ainda são, estudados como se estivessem isolados do contexto histórico, político e social da realidade que se pretende investigar, ou seja, "como se fosse um fenômeno físico, para uma análise acurada, se possível feita em um laboratório, onde as variáveis que o compõem pudessem também ser isoladas, a fim de se constatar a influência que cada uma delas exercia sobre o fenômeno em questão" (LÜDKE e ANDRÉ, 1986 p.3), o que acaba dando espaço a uma neutralidade científica típica das ciências naturais.

Ao longo do desenvolvimento dos estudos no campo da educação, o campo educacional - onde se desenvolve a pesquisa - é tão complexo e dinâmico que não pode ser resumido, apenas, a um estudo analítico, isolando-se algumas variáveis, que exigem o suporte de outros métodos de pesquisa que contemplem algumas instâncias necessárias para uma compreensão mais apurada dos temas em estudo.

Portanto, a pesquisa educacional começa a superar alguns limites até então enfrentados; o pesquisador começa a ter um envolvimento maior com o objeto e o contexto envolvidos na sua pesquisa, fazendo parte do processo de construção do conhecimento, pois a ciência que trata dos problemas da realidade humana, dos problemas do ser humano, tem que levar em consideração o comprometimento do pesquisador com o 
contexto da realidade pesquisada. "O observador é da mesma natureza que o objeto; o observador, ele mesmo, é uma parte da observação" (LEVÍ-STRAUSS, 1975, p. 215).

Com estas preocupações metodológicas, realizamos o recorte de nosso estudo: os projetos ambientais que foram desenvolvidos em um bairro de Bauru/SP, produtos de duas dissertações de mestrado. Partindo dos pressupostos da educação ambiental crítica, este estudo analisou a dimensão participativa dos dois projetos ambientais, com o objetivo de identificar e compreender os indicativos de impactos qualitativos que estes estudos participativos provocaram na organização do ensino escolar e na comunidade, entendendo-a como espaço educativo.

Diante das técnicas utilizadas nos procedimentos da pesquisa qualitativa em educação, elegemos, como instrumento para a categorização dos dados, os procedimentos metodológicos da análise de conteúdo. Esta técnica possui suas raízes nas ciências humanas e tem sido utilizada na maior parte das pesquisas que lidam com dados descritivos como entrevistas, documentos, livros e cartas, entre outros passíveis de análise. Assim, "a ênfase não reside na descrição dos conteúdos, mas no que estes poderão ensinar após serem tratados" (BARDIN, 1979, p. 38), portanto, visa ao aprofundamento da análise.

Ao adotarmos esta técnica de pesquisa, procuramos adequá-la aos objetivos iniciais deste estudo. De acordo com Bardin (1979, p.31), "ao adequá-la ao domínio e ao objetivo pretendidos tem que ser reinventada a cada momento". Dessa maneira, os procedimentos metodológicos utilizados neste estudo foram articulados com os objetivos e com o referencial teórico que assumimos para responder aos nossos questionamentos.

Para esta pesquisa, destacamos que a categoria foi pré-estabelecida: é o processo participativo, visto que o objetivo principal é identificar e analisar a dimensão participativa nas ações ambientais que foram colocadas em prática durante o desenvolvimento dos projetos selecionados para análise, objetivando interpretar os fatores que indicam os eventuais impactos que elas proporcionaram no cotidiano escolar e na comunidade de acordo com as diferentes abordagens filosófico-políticas que elas expressam. Sobre esse aspecto, Bardin (1979, p. 119) salienta que no processo de categorização podemos assumir que: "o sistema de categorias é fornecido e repartem-se da melhor maneira possível os elementos, à medida que vão sendo encontrados".

Para a identificação das ações participativas realizadas nos projetos ambientais, adotamos as três etapas que Bardin (1979) elege como essenciais na organização da análise de conteúdo: pré-análise; exploração do material e interpretação inferencial. Apesar de a autora propor essas etapas, isso não quer dizer que sejam estanques, compartimentalizadas e rígidas, pois, na medida em que as realizamos, percebemos que estão totalmente articuladas, sobretudo aos objetivos propostos. Além disso, a autora ressalta que as etapas podem ser flexíveis, permitindo a introdução de novos procedimentos no decurso da análise.

A pré-análise é a fase de organização e sistematização das idéias iniciais da investigação. A autora coloca como primeiro objetivo a seleção dos documentos a serem analisados. Para efeito deste estudo, selecionamos dois projetos acadêmicos:

- (Re)colorir o presente pela aquarela da memória ambiental: pesquisa-açãoparticipativa em um bairro de Bauru (ALMEIDA, 2005).

- Pesquisa-ação-participativa: compartilhando conhecimentos (JANKE, 2005).

Como segundo objetivo, na etapa da pré-análise, está a formulação de hipóteses que, de acordo com Bardin (1979, p.98), "são as afirmações provisórias que nos propomos verificar, recorrendo aos procedimentos de análise". Partimos da hipótese de que as diferentes abordagens filosófico-políticas praticadas pelos projetos ambientais realizados no 
bairro, geraram fatores indicativos de impacto qualitativos. Portanto, ao analisarmos as ações ambientais contidas nos projetos, tentaremos verificar a validade desta hipótese, com o objetivo de discutir a dimensão participativa, buscando o aprofundamento da reflexão sobre alguns de seus princípios na perspectiva da educação ambiental crítica.

O terceiro e último objetivo, nesta etapa, é a elaboração de indicadores para a extração das categorias em cada projeto; para que estes sejam precisos e seguros é fundamental que a escolha dos mesmos ou as unidades de registro estejam articuladas com as hipóteses do trabalho (BARDIN, 1979, p. 99-100). Logo, como já tínhamos a categoria processo participativo pré-estabelecida, nossas unidades de registro foram os procedimentos que foram utilizados nos projetos para atingirem a dimensão participativa do processo educativo ambiental.

Tendo sido alcançados os objetivos estabelecidos para a etapa da descrição analítica, identificamos o processo participativo contido nos projetos analisados e passamos para a etapa de exploração do material, quando aprofundamos a análise dos projetos para obtenção dos resultados a serem apresentados a partir dos dados extraídos dos textos e administrados de acordo com as decisões tomadas anteriormente.

O esperado é que concomitantemente a esta fase comecem a surgir as primeiras inferências, com base no referencial adotado, para a interpretação dos dados, ou seja, da dimensão participativa. Assim, a etapa da interpretação inferencial, que propiciou a "inferência de conhecimentos relativos às condições de produção; inferência esta que nos fez recorrer a indicadores" (BARDIN, 1979, p.38).

Ao adotarmos a abordagem qualitativa neste estudo, procuramos enveredar por caminhos que não nos levam ao distanciamento entre sujeito e objeto, objetivando a não distinção nesta relação, na medida em que procuramos avançar para além de suas aproximações.

Assim, pretendemos, nos limites deste artigo e a partir da análise e interpretação dos projetos delimitados, contribuir para compreender o processo participativo na educação ambiental, buscando o aprofundamento da reflexão sobre alguns de seus princípios na perspectiva da educação ambiental crítica. Tais princípios estão diretamente relacionados às práticas educativas que estão voltadas para o desenvolvimento de ações ambientais que objetivam a participação e a articulação entre a escola e a comunidade. Este aspecto coloca em evidência as dimensões dialógica, coletiva e participativa do processo educativo ambiental como tentativa de superação dos entraves que dificultam as relações entre a escola e a comunidade, estabelecendo como premissa a centralidade na práxis educativa.

\section{Resultados e discussão}

Os entraves impostos pelo tempo destinado à realização das pesquisas nos Programas de Pós-graduação, além de se constituírem em obstáculos para a execução das investigações, exigem dos pesquisadores grande empenho na busca de sua superação. No caso dos projetos ambientais analisados, (Re)colorir o presente pela aquarela da memória ambiental: pesquisa-ação-participativa em um bairro de Bauru (ALMEIDA, 2005) e Pesquisaação-participativa: Compartilhando conhecimentos (JANKE, 2005), entendemos que este empenho constituiu-se no enfrentamento dos obstáculos encontrados.

Buscando alternativas para o enfrentamento destes entraves, estes dois estudos constituíram-se em um caso original, pois tinham como objetivo a formação de um grupo de pesquisadores comunitários, moradores do bairro. Assim, pesquisadoras se uniram e 
formaram um único Grupo de Pesquisadores Comunitários em um bairro de Bauru/SP, adotando também a mesma metodologia de pesquisa para o desenvolvimento de seus projetos: a pesquisa-ação-participativa. Cabe ressaltar ainda que estas duas pesquisadoras compartilhavam da mesma concepção de educação ambiental. Dessa forma,

\begin{abstract}
realizaram-se duas pesquisas na área da educação ambiental, que tiveram como temas geradores: a história da transformação ambiental do local onde foi construído o bairro, apresentado neste estudo e um outro, tratando dos indicadores de qualidade de vida mais significativos para a comunidade do bairro, apresentado no estudo de Janke (2005). É importante destacar que estes dois trabalhos foram realizados articuladamente: compartilhamos dificuldades, soluções, idéias, leituras, interpretações, descobertas, frustrações, alegrias e angústias. (ALMEIDA, 2005, p. 16).
\end{abstract}

É importante ressaltar, portanto, que consideramos esta iniciativa uma forma de enfrentar os obstáculos impostos pela própria universidade no tocante aos modelos de investigação, as expectativas de produção de conhecimento e até os prazos determinados para a elaboração das dissertações, entre outros obstáculos.

Desta maneira, apresentamos as análises dos dois projetos concomitantemente, pois ambas conduziram o processo participativo de um mesmo grupo de pesquisadores comunitários e compartilharam as mesmas dificuldades, idéias, leituras, descobertas, esforços e investimentos na constituição do grupo, embora cada qual focou e abordou a singularidade de seu estudo.

Almeida (2005) e Janke (2005) discutem o processo de mobilização para a formação do Grupo de Pesquisadores Comunitários. As pesquisadoras entraram em contato com a comunidade por meio da Associação dos Moradores do bairro. Esta escolha decorreu de dois fatos importantes:

o primeiro fato foi que estes moradores já estavam estruturados e organizados em um grupo, o que poderia facilitar na efetivação de uma pesquisa-ação-participativa; o segundo, foi que o grupo representava a comunidade e, como tal, executava tarefas as quais tratavam de temas muito próximos aos que seriam propostos por nós, pesquisadoras acadêmicas. (ALMEIDA, 2005, p. 16-17).

Percebemos que as pesquisadoras, diante do fato de não terem o conhecimento necessário sobre a realidade do bairro, o que se pressupõe ser decorrente de um processo de vivência relativamente longo com a comunidade, buscaram constituir o grupo de pesquisadores a partir de um grupo já organizado e supostamente representativo: a Associação de Moradores. Desta maneira, observamos que esta iniciativa teve o intuito de tornar as condições mais objetivas diante do tempo disponível para o desenvolvimento de uma pesquisa-ação-participativa num curso de mestrado.

Demo (2007, p. 62) enfatiza que a pesquisa participante exige a participação comunitária. Entretanto, o autor ressalta: "não se pode partir da idéia apressada de que a comunidade está 'organizada', porque ignoraríamos sua pobreza política possível". Desta maneira, não podemos negar que a Associação de Moradores do bairro tinha uma organização, porém, temos que considerar que esta organização, embora política, pois representava os interesses de um determinado grupo, não demonstrou ser representativa 
da comunidade, desenvolvendo ações de caráter cultural, patrimonial, religiosa, e até simbólico.

Pela análise empreendida nos projetos, percebemos que as duas pesquisadoras convidaram os membros da Associação de Moradores pressupondo que estes representavam os anseios e necessidades dos moradores do bairro, o que pode ter sido um dos fatores que comprometeu a participação dos demais moradores. Temos que considerar que as pesquisadoras eram estranhas ao bairro e àquelas pessoas, além da falta de tempo necessário para vivenciarem a realidade do bairro.

O tempo despendido na mobilização para a participação da comunidade foi de cinco meses, período em que ocorreram seis encontros com este intuito, durante os quais as duas pesquisadoras encontraram diversos tipos de dificuldades no processo de execução do projeto. Como o objetivo principal de ambas era contribuir para a ocorrência de mudanças em prol de melhorias para a comunidade do bairro, era essencial e primordial que se fizesse a união entre o conhecimento que as pesquisadoras traziam da universidade, o saber popular, a participação dos moradores, e a produção coletiva de conhecimentos para que, juntos, pudessem traçar as estratégias de enfrentamento dos problemas vivenciados (ALMEIDA, 2005).

Ao longo do processo de mobilização, as pesquisadoras também constataram, durante as discussões realizadas com o Grupo, o descontentamento destes participantes, membros da Associação de Moradores, com relação ao envolvimento, comprometimento e participação da comunidade nas atividades do bairro. Frente a esse problema, refletiram sobre a necessidade de "desvincular o Grupo de Pesquisadores Comunitários do grupo da Associação dos Moradores, já que era vontade de todos provocar e incentivar a participação dos demais moradores" (ALMEIDA, 2005, p. 26).

A falta de vivência com a comunidade e a pressão do tempo para a execução do projeto comprometeram, portanto, o delineamento das decisões tomadas frente a este impasse. Analisando, posteriormente, esta situação, podemos identificar a oportunidade, que as pesquisadoras não aproveitaram, para dialogar e refletir no próprio Grupo, de forma mais corajosa e aprofundada, os motivos que determinavam a falta de participação da comunidade nas ações propostas pela Associação de Moradores, superando a percepção superficial dos membros da diretoria da Associação participantes dos projetos de que os moradores "não tem interesse por nada". Talvez, dessa forma, tivessem conseguido direcionar melhor as estratégias que utilizariam para incitar a participação dos demais moradores para a formação do Grupo.

Durante a mobilização para agregar novos membros ao Grupo, as pesquisadoras lançaram mão de diversas estratégias coletivas. Ao longo das reuniões organizaram as ações: elaboraram convites informativos, distribuíram panfletos, exibiram faixas em espaços estratégicos, fixaram cartazes nos veículos de transporte, alugaram um "carro de som" para anunciar as reuniões, publicaram uma matéria no Jornal da Associação de Moradores divulgando o convite, adotaram um slogan e um logotipo enfatizando a formação de um grupo de pesquisadores acadêmicos e comunitários, buscando, assim, uma identidade com os moradores. Não bastando todos esses investimentos e estratégias, prepararam para a sexta e última reunião, destinada a agregar novos participantes ao grupo, a elaboração de uma apresentação coletiva dos principais objetivos do grupo. Para isso, os pesquisadores as acadêmicas e os comunitários - identificaram os principais problemas do bairro para apresentarem aos demais moradores: esses foram os primeiros resultados da produção de conhecimentos sobre o próprio bairro que caracterizou as ações como pesquisa-açãoparticipativa. Os dados estavam relacionados à educação, ao ambiente, à segurança, ao 
lazer e à saúde e foram apresentados coletivamente pelos cinco componentes do grupo como os principais pontos de discussão, objetivando agregar a participação dos demais moradores na formação do grupo para organizarem suas ações. Apesar de todos estes investimentos nas estratégias utilizadas para mobilizar a comunidade, o grupo manteve-se com os mesmos integrantes com que havia começado.

Cabe ressaltar a importância de considerarmos os fatores determinantes que influenciam a falta de participação popular na sociedade em geral, pois, afinal, partimos do pressuposto de que a realidade é síntese de múltiplas determinações. A falta de compromisso, o desinteresse e a falta de participação dos moradores do bairro com relação às questões aparentemente "comuns" a todos, além das determinações relacionadas à representatividade - ou a falta dela - da diretoria da Associação dos Moradores, são determinadas também pela tendência neoliberal massificada de preconização do consumismo e sua promoção da individualidade em detrimento da valorização do sentimento de interesses comuns e coletividade.

Assumindo os anseios de uma comunidade, num projeto de pesquisa-açãoparticipativa, não podemos apenas incorporá-los de forma acrítica. É importante ir além, o que não quer dizer que não devemos levar em conta a concepção de mundo que estas pessoas possuem, desrespeitando suas práticas sociais. Pelo contrário, a partir da construção do Grupo, do respeito e da confiança entre seus membros, é importante criar condições para a instrumentalização dos sujeitos que, envolvidos num processo educativo, objetivem a conquista da autonomia (SAVIANI, 2005).

Percebemos, portanto, diversos obstáculos enfrentados pelas pesquisadoras na busca por novos participantes do Grupo de Pesquisadores Comunitários. Apesar da falta de sucesso dos esforços empreendidos por elas, os cinco integrantes comunitários assumiram a responsabilidade, enquanto Grupo, para enfrentar os desafios propostos inicialmente: a construção coletiva de conhecimentos sobre a história das transformações ambientais do bairro e sobre o levantamento dos indicadores de qualidade de vida daquele local para propor algumas ações coletivas.

Durante o processo de análise, as pesquisadoras consideraram os conhecimentos e vivências dos moradores em relação às características sócio-ambientais existentes. Assim, buscando fundamentar seus objetivos nos pressupostos da pesquisa-ação-participativa, Janke $(2005$, p. 26) destaca que,
para essa metodologia, voltar a atenção ao olhar de quem vivencia a realidade, dar importância ao senso comum, é o próprio método de investigação, enquanto que para a ciência clássica é retroceder a um ponto anterior ao da hegemonia científica.

Neste fragmento observamos que os estudos buscaram romper com os paradigmas clássicos das ciências. No entanto, consideramos que tal postura deve ser analisada com algumas ressalvas para que, ao ser colocada em prática, não recaia em um reducionismo científico. É importante frisar que o fato de dar importância ao senso comum, especialmente daqueles que se encontram em uma posição menos privilegiada na estrutura social não significa dizer que devemos assumir as concepções dos sujeitos tal como elas se apresentam num primeiro momento, já que, em diversos momentos, são frutos da vivência imediata da realidade humana.

Sobre este aspecto, Loureiro (2007, p. 25) afirma que "em sentido dialético, um dos eixos que movimenta a sociedade e estabelece a possibilidade de sua superação é a ação consciente dos que se encontram em posição de subordinação nas relações sociais 
vigentes". Esta formulação coloca a necessidade de instrumentalizar os sujeitos para as ações conscientes e críticas acerca da realidade. Portanto, ao destacar a importância dos conhecimentos do senso comum, entendemos que estes não devem ser menosprezados ou excluídos, mas devem ser incorporados num processo democrático de ação reflexiva, articulando a prática e o senso comum à teoria, na tentativa de superar a realidade excludente.

Encontramos diversos autores na literatura científica que analisam criticamente os paradigmas que fundamentam a hegemonia da ciência clássica (LOUREIRO 2007; TOZONIREIS, 2007b), especialmente no que diz respeito ao distanciamento entre o sujeito e o objeto. No entanto, entendemos que a aproximação com o objeto, colocando-o como sujeito do processo, não pode ter a finalidade de inverter radicalmente os pólos do processo, dando ênfase apenas à prática social dos sujeitos.

Para Tozoni-Reis (2007b), o que deve ser radical é a participação do sujeito neste processo, o que não pressupõe a secundarização do pensamento científico em relação ao senso comum, já que esta posição não possibilita o enfrentamento dos problemas, sejam eles ambientais ou não. Daí a importância do processo educativo para a instrumentalização do sujeito. Ao se apropriar de conteúdos mais elaborados, num processo participativo, o sujeito tem possibilidade de aprender e de exercer sua cidadania, buscando resolver os problemas sem limitar-se à sua prática (SAVIANI, 2005). Neste sentido, Loureiro (2007, p. 26) afirma:

O compromisso político com a emancipação é aqui entendido não no sentido iluminista de libertar pela razão o ser humano de todos os limites que a existência nos impõe, o que seria imaginar o plano das idéias puras, da eliminação das contradições práticas da vida, mas como movimento de libertação consciente e de superação permanente de alienação material e simbólica, coletiva e individual, existentes em cada fase historicamente definida.

Este é mais um dos desafios da pesquisa-ação-participativa e, para atingir os objetivos desta, é necessário que o grupo esteja preparado para enfrentar uma situação semelhante. Nesta perspectiva, um dos mais importantes princípios da pesquisa-ação-participativa em educação ambiental é a participação:

A primeira e mais simples, porém mais complexa idéia é que participação é, principalmente, um processo de parceria, real e objetiva, na tomada de decisões coletivas (grifo nosso). Etimologicamente participar - ou "participare", do latim - significa "tomar parte". É, portanto, uma ação coletiva que sugere tomar decisões, decisões coletivas. (TOZONI-REIS, 2007b, p. 152).

Neste fragmento percebemos que o processo participativo não é considerar a comunidade como um objeto de pesquisa ou, ainda, como mais um membro que "faz número" junto ao grupo. O processo participativo na pesquisa-ação-participativa exige tratar os membros do grupo como sujeitos da pesquisa, sendo, portanto, necessária a participação radical de todos os envolvidos no processo (TOZONI-REIS, 2007b).

Os objetivos propostos por Almeida (2005), a construção coletiva do processo histórico de ocupação do bairro por parte dos sujeitos envolvidos na pesquisa, e os objetivos propostos por Janke (2005), a construção coletiva dos indicadores da qualidade de vida por 
parte dos sujeitos envolvidos na pesquisa, fizeram com que as pesquisadoras utilizassem as técnicas e instrumentos da história oral para atingirem tais objetivos.

É justamente sobre este aspecto que o desafio se instala: como garantir a participação radical dos pesquisadores comunitários, uma vez que não "dominam" os procedimentos metodológicos da história oral para colocá-los em prática? Eis um dos pontos a ser discutido: a necessidade de instrumentalizar os sujeitos, durante o processo educativo da pesquisa-ação-participativa.

Assim, as reuniões que se sucederam nessa fase da pesquisa foram diretivas, visto que os pesquisadores comunitários não dispunham dos procedimentos metodológicos para coleta de dados, a história oral. As pesquisadoras acadêmicas explicaram "o fazer pesquisa; quais as etapas de uma investigação; como a pesquisa permite que conheçamos mais profundamente nossa realidade e outros aspectos referentes à natureza das investigações" (ALMEIDA, 2005, p. 44).

Todos os procedimentos, necessários para a realização da coleta de dados sobre as transformações ambientais que aconteceram no local onde foi construído o bairro, bem como o levantamento dos indicadores de qualidade de vida referentes àquele local, foram desenvolvidos a partir de discussões coletivas, partindo-se da prática social dos pesquisadores comunitários, durante a realização do sétimo encontro. Após os esclarecimentos dos objetivos da pesquisa, os membros do grupo passaram a discutir sobre as possibilidades metodológicas que, teoricamente, responderiam às indagações da pesquisa, traçando o delineamento sobre quais eram as informações desejadas, como seria a coleta de dados e qual tratamento seria dado às informações coletadas, enfatizando a necessidade de se propor uma ação da própria comunidade diante dos resultados obtidos. Discutiram, também, quais as pessoas que deveriam ser entrevistadas.

Durante a realização do nono encontro todos os membros apresentaram os resultados obtidos durante a coleta de dados e relataram suas experiências como entrevistadores, bem como as dificuldades que haviam enfrentado e as observações que haviam feito; também ouviram algumas das entrevistas que haviam sido gravadas pelos pesquisadores comunitários. Desta maneira, o processo de análise dos dados se iniciava, possibilitando a apropriação de conhecimentos por parte dos pesquisadores:

Pudemos observar a força do processo de descoberta por parte dos pesquisadores-participantes. Descoberta da importância da pesquisa, de que o processo organizado de investigação permite um conhecimento mais detalhado e aprofundado sobre determinado tema e de que, mesmo já conhecendo parte da história de seu bairro e as necessidades de sua comunidade, isto nunca havia sido organizado e sistematizado, dificultando o enfrentamento dos problemas por parte da Associação dos Moradores do Bairro. (ALMEIDA, 2005, p. 62).

Este relato sinaliza a importância do processo educativo da pesquisa-ação-participativa, pois, a partir da prática social dos pesquisadores comunitários, criou-se a oportunidade de, por meio de um processo coletivo e participativo, se instrumentalizarem dos conhecimentos relativos aos procedimentos de uma pesquisa.

No entanto, o mesmo não foi atingido em relação à reflexão crítica sobre os problemas ambientais relacionados à história das transformações ambientais e à qualidade de vida da comunidade do bairro. Eis o principal desafio a ser assumido diante de propostas de ação que visam à superação de problemas ambientais, a partir de um processo educativo 
ambiental e na perspectiva crítica. Tal desafio torna-se ainda maior quando se trata de projetos participativos junto à comunidade.

Sintetizando, os conhecimentos na busca da transformação da realidade pelos sujeitos ficaram comprometidos, pois a falta de participação dos sujeitos enquanto grupo, assim como a falta de tempo, não permitiu que aquela ocorresse. Isso não significa dizer que os sujeitos não tiveram a oportunidade de se apropriar dos conhecimentos trabalhados no processo de desenvolvimento da pesquisa, especialmente em relação ao processo metodológico.

\section{Considerações finais}

Nossas discussões sinalizam que a mobilização para a participação não se esgota nos investimentos e esforços em busca de estratégias, reflexões e discussões coletivas, mas, também, de tempo para que se configure como um processo grupal, que transforme os envolvidos em verdadeiros parceiros e participantes. Estas reflexões sinalizam que a escolha de alternativas pragmáticas e práticas para um projeto desta natureza, pode comprometer os esforços empreendidos na formação de um grupo de pesquisa-ação-participativa, não resultando no caminho mais adequado para atingir seus objetivos.

Não obstante, vimos que o processo participativo e coletivo tem que ir além do compartilhamento de experiências e conhecimentos práticos, caso contrário, não criará condições para a superação dos problemas da realidade. Queremos dizer que a dimensão participativa tem que levar em conta, sem dúvida alguma, a prática social dos sujeitos, mas não pode limitar-se a esta dimensão. Neste caso, embora tenha uma perspectiva qualitativa em relação à metodologia, a dimensão participativa acaba tratando os sujeitos como objetos, não proporcionando condições concretas para que estes, enquanto sujeitos do processo, incorporem o processo de instrumentalização para enfrentarem a realidade social à luz de um conhecimento mais elaborado, visando à transformação das relações sociais (SAVIANI, 2005).

\section{Referências}

ALMEIDA, I. P. (Re)colorir o presente pela aquarela da memória ambiental: pesquisaaçãoparticipativa em um bairro de Bauru. 2005. 165f. Dissertação (Mestrado em Educação para Ciências) - Universidade Estadual Paulista, Faculdade de Ciências, Bauru, 2005.

BARDIN, L. Análise de conteúdo. Lisboa: Edições 70, 1979.

BOGDAN, R. C.; BIKLEN, S. K. Investigação qualitativa em educação. Portugal: Porto Editora, 1991.

DEMO, P. Pesquisa Participante: usos e abusos. IN: TOZONI-REIS, M. F. de C. (Org.) A pesquisa-ação-participativa em educação ambiental: reflexões teóricas. São Paulo: Annablume; Fapesp; Botucatu: Fundibio, 2007, p. 57-81.

GRÜN, M. Ética e educação ambiental: a conexão necessária. 11ª Ed, Campinas: Papirus, 2007. 
JANKE, N. Pesquisa-ação-participativa: compartilhando conhecimentos. 2005. $128 f$. Dissertação (Mestrado em Educação para Ciências) - Universidade Estadual Paulista, Faculdade de Ciências, Bauru, 2005.

LÉVY-STRAUSS, C. Aula Inaugural. In: ZALUAR, A. (org.) Desvendando Máscaras Sociais. Rio de Janeiro: Francisco Alves, 1975, p. 211-244.

LOUREIRO, C. F. B. Pesquisa-ação participante e educação ambiental: uma abordagem dialética e emancipatória. In: TOZONI-REIS, M. F. C. A pesquisa-ação-participativa em educação ambiental: reflexões teóricas. São Paulo: Annablume; Fapesp; Botucatu: Fundibio, 2007.

LOUREIRO, C. F. B. Trajetórias e Fundamentos da Educação Ambiental. São Paulo: Cortez, 2004.

LÜDKE, M.; ANDRÉ, M. E. D. A. Pesquisa em Educação: Abordagens Qualitativas. São Paulo: E.P.U., 1986.

SAVIANI, D. Escola e democracia. 38ª Ed. Campinas: Autores Associados, 2006.

SAVIANI, D. Pedagogia Histórico-Critica. Campinas: Autores Associados, 2005.

TOZONI-REIS, M. F. C. Contribuições para uma pedagogia crítica na educação ambiental: reflexões teóricas. In: LOUREIRO. C.F.B. A questão ambiental no pensamento crítico: natureza, trabalho e educação. Rio de Janeiro: Quartet, 2007a, p. 177-221.

TOZONI-REIS, M. F. C. A pesquisa-ação-participativa e a educação ambiental: uma parceria construída pela identificação teórica e metodológica. In: TOZONI-REIS, M.F.C. A pesquisaação-participativa em educação ambiental: reflexões teóricas. São Paulo: Annablume; Fapesp; Botucatu: Fundibio, 2007b, p. 121-161.

TRAJBER, R.; MENDONÇA, P. R. (Orgs). Educação na diversidade: o que fazem as escolas que dizem que fazem educação ambiental. Brasília: Secretaria de Educação Continuada, Alfabetização e Diversidade, 2006.

VIEZZER, M. L. Pesquisa-ação-participante (PAP): origens e avançOs. In: FERRARO-JUNIOR, L. A. (Coord.). Encontros e Caminhos: formação de educadoras(es) ambientais e coletivos educadores. Brasília: Ministério do Meio Ambiente, Diretoria de Educação Ambiental, 2005. p.277-294. 